\title{
Mondor's disease: sclerosing thrombophlebitis of subcutaneous veins in a patient with occult carcinoma of the breast
}

\author{
SN Wong *, FHKAM (Family Medicine), Loretta KP Lai, MFM (Monash), FHKAM (Family Medicine), PF Chan, MOM (CUHK), \\ FHKAM (Family Medicine), David VK Chao, FRCGP, FHKAM (Family Medicine)
}

Department of Family Medicine and Primary Health Care, Kowloon East Cluster, Hospital Authority, Hong Kong

*Corresponding author: wongsn1@ha.org.hk

Hong Kong Med J 2017;23:311-2

DOI: 10.12809/hkmj154699

\section{Case report}

In March 2011, a 47-year-old Chinese woman who enjoyed good past health presented to a local general out-patient clinic in Hong Kong with a 2-week history of a mildly painful cord-like structure stretching from the inferior part of the left breast to the umbilicus level (Fig). She had worked as a dishwasher 3 months prior to the appearance of the lesion, a job that required her to carry stacks of heavy dishes. There was no recent trauma or surgery of the breast and no family history of breast cancer. Physical examination revealed a $15-\mathrm{cm}$ long by 0.5-cm wide erythematous subcutaneous cord-like lesion stretching from the inferior part of the left breast down along the anterolateral chest wall to the umbilicus level. The lesion was firm and mildly tender. It was adherent to the skin, but was slightly movable over the deeper tissues. Examination of the breasts showed no asymmetry or skin changes. Palpation of the right breast was normal. There was, however, mild lumpiness over the outer upper quadrant of the left breast although no definite breast lump found. The nipples were normal with no discharge. There were no palpable axillary or regional lymph nodes.

The patient was diagnosed with Mondor's disease with involvement of the thoracoepigastric vein. The course of the disease was explained and the patient was advised to avoid repetitive strain of the chest wall. Paracetamol was prescribed for symptomatic relief. She was referred to the Surgical Specialist Outpatient Clinic (SOPC) for further evaluation of left breast lumpiness. The cord in this patient disappeared spontaneously after approximately 5 weeks. Clinical assessment at the SOPC in May 2011 did not identify any palpable breast lump. Routine mammogram was later performed in August 2012 and revealed a 2-cm illdefined high-density speculated lesion in the outerupper quadrant of the left breast. Supplementary ultrasonography was also performed and revealed an ill-defined irregular hypoechoic lesion measuring $0.7 \times 0.6 \times 1.65 \mathrm{~cm}$. The patient was followed up in the SOPC 2 weeks later and the lesion was also clinically palpable. Core biopsy confirmed invasive

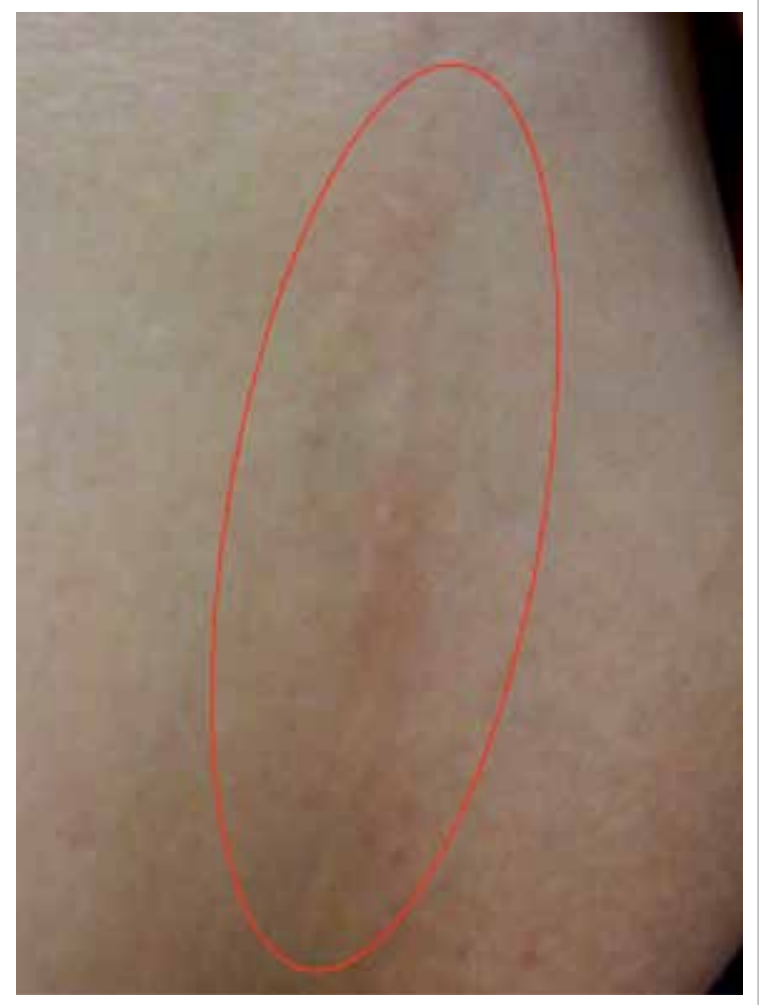

FIG. The longitudinal cord-like lesion over the left abdominal wall on presentation

ductal carcinoma. Left modified radical mastectomy was performed with metastatic invasive ductal carcinoma and axillary lymph node involvement confirmed (stage pT1cpN1). The patient was also treated with adjuvant chemotherapy.

\section{Discussion}

Mondor's disease is an uncommon clinical condition of thrombophlebitis of the subcutaneous veins of the anterolateral thoracoabdominal wall. The most commonly affected vessels are the thoracoepigastric, lateral thoracic, and superior epigastric veins. ${ }^{1}$ It is characterised by sudden onset of one or more 
subcutaneous palpable and visible cord(s) over the mammary area, chest wall, or epigastrium.

Mondor's disease occurs most commonly in middle-aged patients, and is more common in women than in men (ratio 3:1). ${ }^{2}$ The involved subcutaneous veins will initially turn red and tender and subsequently become a painless and tough fibrous band. Pathologically, the first stage is due to infiltration of inflammatory cells resulting in obliterative thrombophlebitis of the affected veins, causing redness and tenderness. In the second stage, connective tissues proliferate in the vessels with consequent formation of the fibrous band. ${ }^{1}$ Recanalisation of the veins occurs later and the fibrous band will disappear within several weeks. ${ }^{3}$

It is thought to be a very uncommon disease although the true incidence is unknown as it is selflimiting and patients may not seek medical attention. The diagnosis can usually be made based on clinical history and typical physical findings. Biopsy is not essential.

The aetiology of Mondor's disease is still unclear. In many cases it is idiopathic, although it has also been linked with recent breast surgery, local trauma, excessive physical activity with muscle strain, an inflammatory process, infections, and mammary pathology including mastitis or abscess. ${ }^{2}$ Association with breast cancer has also been reported. Catana et $\mathrm{al}^{4}$ studied 63 cases of Mondor's disease of whom eight (12.7\%) had associated breast cancer. The authors suggested that mammography should be performed in patients with Mondor's disease even when physical examination was normal. A retrospective review in 2011 identified five cases of Mondor's disease of the breast; none of which was associated with breast cancer. ${ }^{5}$ Nonetheless, the authors advised thorough evaluation of the breast to exclude an underlying breast cancer. In our patient, the correlation with an occult carcinoma of the breast could not be confirmed since there was a time delay between the presentation of Mondor's disease and the diagnosis of breast carcinoma. Moreover, the patient's recent strenuous job with repetitive straining of the chest wall muscle might have been a predisposing factor.

Since Mondor's disease is self-limiting, symptomatic treatment is suggested. General advice includes rest, local application of heat, and better breast support. Oral non-steroidal antiinflammatory drugs provide effective symptomatic relief. $^{2}$

In summary, Mondor's disease is a condition that is rarely encountered in primary care. Recognising this condition is important as it can avoid unnecessary investigations and referral for diagnosis. Although the association of underlying breast cancer with Mondor's disease has not been confirmed, family physicians should be aware of the possibility and conduct a thorough evaluation including clinical examination and imaging of the breast to exclude its presence in patients diagnosed with Mondor's disease.

\section{References}

1. Alvarez-Garrido H, Garrido-Ríos AA, Sanz-Muñoz C, Miranda-Romero A. Mondor's disease. Clin Exp Dermatol 2009;34:753-6.

2. Mayor M, Burón I, de Mora JC, et al. Mondor's disease. Int J Dermatol 2000;39:922-5.

3. Ichinose A, Fukunaga A, Terashi $\mathrm{H}$, et al. Objective recognition of vascular lesions in Mondor's disease by immunohistochemistry. J Eur Acad Dermatol Venereol 2008;22:168-73.

4. Catana S, Zurrida S, Veronesi P, Galimberti V, Bono A, Pluchinotta A. Mondor's disease and breast cancer. Cancer 1992;69:2267-70.

5. Salemis NS, Merkouris S, Kimpouri K. Mondor's disease of the breast. A retrospective review. Breast Dis 2011;33:1037. 